\title{
ADDENDUM TO: THE VARIATIONAL THEORY OF GEODESICS
}

\author{
BY RICHARD SACKSTEDER
}

Several people have pointed out that in my review of The variational theory of geodesics, I overlooked the fact that the original Russian version had a preface which acknowledged the author's reliance on the work of Helgason and others. Unfortunately, this preface was not included in the English translation; however, the publisher has now added a preface which indicates the author's sources.

\section{ADDENDUM, VOLUME 76}

Paul Ponomarev, Class numbers of positive definite quaternary forms, pp. 646-649.

Page 646, line 1: Insert "of dimension four" after "vector space". 